\title{
Body Experience of Burnout-patients
}

\section{David Duncan}

Movement and Sports Pedagogy Research Group, Institute of Sports Science, University of Graz, Graz, Austria

\begin{abstract}
Background: The burnout syndrome has been the subject of numerous researches over the last decades, helping to analyze, identify and classify the spreading illness. This article aims to combine the selfreflected knowledge of Burnout-patients and scientific data. Furthermore, it will give a short overview of the topic body-experience, namely body image, body satisfaction and body differentiation and show how Burnout-patients stack up against healthy people in these areas.

Method: To explore the topics of conception, satisfaction and level of differentiation, a Colour-a-PersonDissatisfaction-Test (Köperbildmaltest), is used to explore dysfunctions of the body experience.

Setting: 83 Colour-a-Person-Dissatisfaction-Tests were carried out. 47 were conducted with patients, who were hospitalized at a clinic. The control group consisted of 36 participants, all working for the same company and diagnosed as "healthy" by the company's occupational physician.

Results: Results show a significant difference between Burnout-patients and the control group regarding the areas of body satisfaction and differentiation. Furthermore, it was useful to divide the Burnoutpatients into sub-categories and analyse their body conception in comparison to the fellow patients. The findings show how the levels of satisfaction and differentiation develop over the course of their hospitalization.

Conclusion: Compared to Burnout-patients, the control group shows a higher level of satisfaction and differentiation, which leads to the conclusion that Burnout-patients not only suffer from emotional exhaustion, but that also their conception of their body is dysregulated. Similar pathologies are described with other diseases as well, e.g. anorexia nervosa, adiposity and bulimia nervosa. It can be assumed that the body image and the perception of the body of Burnout-patients are as dysregulated as the ones of patients with other psychological disturbances.
\end{abstract}

\section{Publication History:}

Received: September 10, 2016

Accepted: January 18, 2017

Published: January 20, 2017

\section{Keywords:}

Burnout-Syndrome, Body image, Body experience,

Körperbildmaltest, Colour-APerson-Dissatisfaction-Test, Bodysatisfaction, Body-differentiation

\section{Background/ Introduction}

Having a "burnout" seems to have become a mass phenomenon receiving constant media attention.

The number of employees, who miss work due to psychogenic illnesses is on a constant rise. Since the year 2000, the amount of days of absence in Germany, caused by mental and emotional suffering, has risen by an astronomical $1.400 \%$, according to Richter [1].

Since 2004, the numbers of cases of inability to work, due to burnout-related symptoms, like fatigue and listlessness, have exploded. For example, in the year 2004, 0.6 days of work were missed per 100 employees on an average in Germany, whereas in 2011 already an average of 9 days were missed as a result of these symptoms, that is 15 times more. And the numbers are rising constantly [1].

The survey by the National-Association of Psychotherapists in Germany (BPtK) states further [1], that the average time of leave of a burnout-patient amounts to 30 days per year, which adds up to costs of 26 billion Euros per year for the German national economy [1].

Not only in Germany, also in Austria, doctors are ringing the warning bells. A recent study states, that 3 million (of 7.5 million) Austrians suffer from sleep disorder, while 1.5 million Austrians are vulnerable to burnout [2].

The term "burnout" was coined in the 1970s by the American psychologist Herbert Freudenberger. He used it to describe the consequences of severe stress and high ideals experienced by people working in "helping" professions. Doctors and nurses, for example, who sacrifice themselves for others, would often end up being "burned out" - exhausted, listless, and unable to cope. Nowadays, the term is not only used for these helping professions, or for the dark side of self-sacrifice. Anybody seems to be at risk: stressed-out careerists and celebrities, over-worked employees, or homemakers. "[3] In 1981, a furtherreaching definition was introduced by Maslach, alongside an instrument for the measurement of burnout - the Maslach Burnout Inventory, which is still the most frequently used tool today [4].

In the Western world, the public interest in the burnout syndrome has increased immensely over the last few years, also due to constant media attention, reporting about "burnt-out" celebreties, such as Demi Moore, Mariah Carey and Eminem [5].

However, it needs to be addressed that there seems to be a big discrepancy between published opinion and specific knowledge. As the burnout syndrome tends to be mixed up with work-related stress in the media, everybody thinks of him- or herself as a specialist. This is quite understandable, as mostly everyone has experienced negative emotions inflicted by work-related stress over his or her workingcareer.

"Corresponding Author: David Duncan, Movement and Sports Pedagogy Research Group Institute of Sports Science, University of Graz, Mozartgasse 14 A-8010 Graz, Austria; E-mail: david.duncan@uni-graz.at

Citation: Duncan D (2017) Body Experience of Burnout-patients. Int J Phys Ther Rehab 3: 125. doi: https://doi.org/10.15344/2455-7498/2017/125

Copyright: (c) 2017 Duncan et al. This is an open-access article distributed under the terms of the Creative Commons Attribution License, which permits unrestricted use, distribution, and reproduction in any medium, provided the original author and source are credited. 
The burnout syndrome has been the subject of numerous researches, carried out by psychologists and sociologists over the last decades, helping to analyze, identify and classify the spreading illness. The main problem for science research is caused by the simple fact, that there is no generally accepted definition of burnout, as the separation from other illnesses and disorders is difficult.

\section{Definition}

According to Maslach and Jackson, burnout is the result of chronic stress (work-related), which has not been successfully dealt with. It is characterized by exhaustion and depersonalization (negativism/ cynicism) and is found predominantly in caring and social professions (e.g. social workers, teachers, nurses, doctors, dentists) [4].

In the 10th revision of the International Classification of Diseases (ICD 10) the term 'burnout' was described under Z.73.0 as 'Burnoutstate of total exhaustion' [6].

Contrary to earlier observations regarding the epidemiology of burnout, it has been noted that the syndrome is not associated with certain workplaces, circumstances, sex or age. The occurrence of burnout syndrome has been described in diverse occupations, e.g. in social workers, advisors, teachers, nurses, laboratory workers, speech therapists, ergo therapists, doctors and dentists, police and prison officers, stewardesses, managers, and even in housewives, students and unemployed people. Psychological explanations assume that in most of these occupations the combination of caring, advising, healing or protecting, coupled with the demands of showing that one cares, is of central importance. The prevalence rates published in the literature for individual occupations must be regarded skeptically, as the definitions and diagnostic criteria used are not uniform. Depending on the evaluation instruments and classification systems used, an incidence of burnout in teachers of up to $30 \%$ has been given. For doctors and dentists more recent studies give prevalence rates of up to $10 \%[7]$.

\section{Symptoms of the Burnout-syndrome}

Patients who suffer from Burnout show a wide variety of symptoms, such as psychiatric, psychosomatic, somatic and social disorders. People affected from Burnout report of chronic fatigue and continuous exhaustion, concentration and memory disturbances, a lack of precision and even a lack of drive, for example a lack of interest, cynicism and aggressiveness towards their social surrounding. Furthermore, severe disturbances, such as anxiety and depressive disturbances are linked to the Burnout-syndrome. The range of somatic symptoms include headaches, gastro-intestinal disorders (irritable stomach, diarrhea), or cardio-vascular disturbances such as tachycardia, arrhythmia, and hypertonia [7].

As Burnout can be seen as a process, sometimes lasting many years, the range of symptoms always depend on the duration and severity of the illness. Even negative social consequences can be linked with the syndrome, such as, from the point of view of the individual, withdrawal at the workplace (so called 'inner resignation') or effects on private life (partner/ sexual problems, social isolation). From the perspective of society, there is an increased risk of repeated or long periods of absence from work and early invalidity [7].

Freudenberger describes the Burnout-syndrome in twelve stages [8], and links each stage with certain symptoms. It has to be clarified, that the duration of each stage is highly individual, some can last for months, some for days and some may be skipped altogether. It is also not unheard of, that patients go back and forth between stages, as these overlap. Also healthy people experience certain stages of this cycle, as stress occurs in every working-situation - however, a healthy person will fall back to a healthy state, once the stressful situation is mastered.

\section{Object of research}

As mentioned above, this study intends to combine self-reflected knowledge and scientific data.

After numerous researches, the symptoms of the Burnout-syndrome have been well documented. However, one question remains mainly unanswered - How do the people affected experience their own body? Litzke and Schuh [9] argue, that burnout-patients do not "feel" their bodies like healthy people, and this article intends to show, how the body of burnout-patients is represented in their minds and what kind of difference is there to the experience of healthy people.

To understand the concept of mental representation of one's body, the term "body image" will be explained, before the actual study will be introduced.

\section{Body image}

"The picture of our own body which we form in our mind, that is to say the way in which the body appears to ourselves". [10] The body image is "the picture of our own body which we form in our mind, that is to say the way in which the body appears to ourselves". [10]

The phrase body image was first coined by the Austrian neurologist and psychoanalyst Paul Schilder [11]. A person's body image is thought to be, in part, a product of their personal experiences, personality, and various social and cultural forces. A person's sense of their own physical appearance, usually in relation to others or in relation to some cultural "ideal," can shape their body image. A person's perception of their appearance can be different from how others actually perceive them. [12] The body image is a "psychological experience which focuses on the feelings and attitude towards the own body" [13], in other words the body image is a combination of all positive and negative feelings a person carries towards his or her own body. Bielefeld [15] defines "body image" as the psychologicalphenomenological section of body experience, which includes all emotional-affective performances of the individual regarding the own body. According to Bielefeld, body experience (Körpererfahrung) is the sum of body scheme (Körperschema) and body image (Körperbild). Body scheme includes the areas of body orientation (Körperorientierung), body size estimation (Körperausdehnung) and body knowledge (Körperkenntnis) and, due to phenomenological nature of the underlying study of this article, was not investigated, as body scheme is defined as the neurophysiological section of body experience, whereas the field of body image comprises all psycho-phenomenological subfields of body experience. Bielefeld carries on to divide the term "body image" into three subcategories, namely body consciousness (Körperbewusstsein), body boundary (Körperausgrenzung) and body attitudes (Körpereinstellung). Body consciousness is the psychological representation of one's body, or parts of it, in the conscience of an individual. Body boundary represents the experience of bodily borders, meaning the ability differentiate between body and surroundings. Body attitude, also called body satisfaction, stands for the sum of attitudes towards the own body and furthermore the skills to interpret body signals, such 
as pain and tension. The combination of these three categories is described as "body image" by Bielefeld, who adds, that it is a schematic concept of the own body, the individual creates through internal and external perceptual processing. Bielefeld carries on to define body experience as the "sum of all experiences with the own body, gathered over the course of individual and social development, which can be both cognitive and affective, conscious and unconscious.

The satisfaction with the body is also an item of interest in this study. The item in question in this case is, how the patients evaluate the different parts of their body - do they have rather positive or negative feelings towards it.

\section{Body differentiation}

Beside the question of satisfaction with their body, patients were also tested on how differentiated they are able to feel their body? It is argued in specialist literature that patients who suffer from psychological disturbances experience their body less differentiated than healthy people [12]. Furthermore, it can be said, that people who do not "feel" their own body and their needs are highly endangered of suffering from burnout, as they neglect the symptoms and warning signs their body sends out $[16,17]$. To "feel" one's body, a person has to be able to differentiate his or her body. Müller [14] argues, that a high level of differentiation leads to a stable integration of the body image into one's mind and therefore also leads to a stable concept of oneself, which is vital to avoid Burnout and other psychological malfunctions. To be able to focus on areas of dissatisfaction goes hand in hand with not feeling dissatisfied with the body as a whole, only due to a malfunction of one body part, thus stabling the concept of oneself. Once a person is able to distinguish that an impairment of one body area does not lead to a breakdown of the entire system, but rather is something that can be corrected if focused on, the way is pathed to a healthier self.

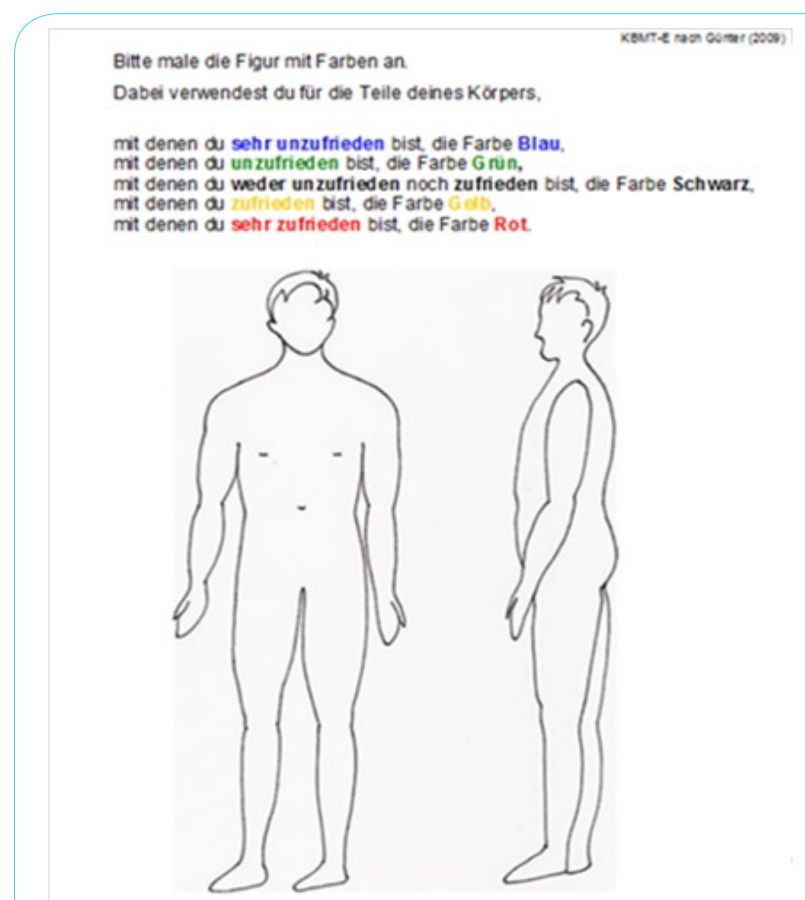

Figure 2: Colour-a-Person-Dissatisfaction-Test (Körperbildmaltest) male schema.

\section{Materials \& Method}

The Colour-a-Person-Dissatisfaction-Test (Körperbildmaltest) was designed by Günter [16] for the testing of children, later adapted for adults by Geiger [18]. The layout was modified by Glawischnig [20] to serve as a testing tool for grownups. This test holds the advantage, according to Günter, that the body experience is portrayed visually and graphically, in contrast to most questionnaires and interviews, which have to rely on the ability of the interviewee to depict their feelings towards their body verbally, which is often a challenge. Furthermore, this test offers the opportunity to not only investigate the patients' satisfaction with their body, but also analyze their ability to differentiate their body.

The Colour-a-Person-Dissatisfaction-Test (Körperbildmaltest) includes two schematic outlines of the figure of an adult, according to the sex of the interviewee (see Fig. 2 and Fig. 3), showing both a frontal and a lateral figure. Above those, the interviewee can find directions on how to fill out the schemes. These directions were also read out by the interviewer and clarified if needed. To avoid misunderstandings, the directions were formulated as simple as possible. Also the portraiture of the genital area and nipples was forgone, to prevent any kind of misinterpretation.

The following text was found on each Colour-a-Person-DissatisfactionTest (Körperbildmaltest):

Please colour the figure.

Use the following colours fort he parts oft he body: BLUE for the areas you are very unsatisfied with, GREEN for the areas you are unsatisfied with,

BLACK for the areas you are neither unsatisfied, nor satisfied with, YELLOW for the areas you are satisfied with and RED for the areas you are very satisfied with.
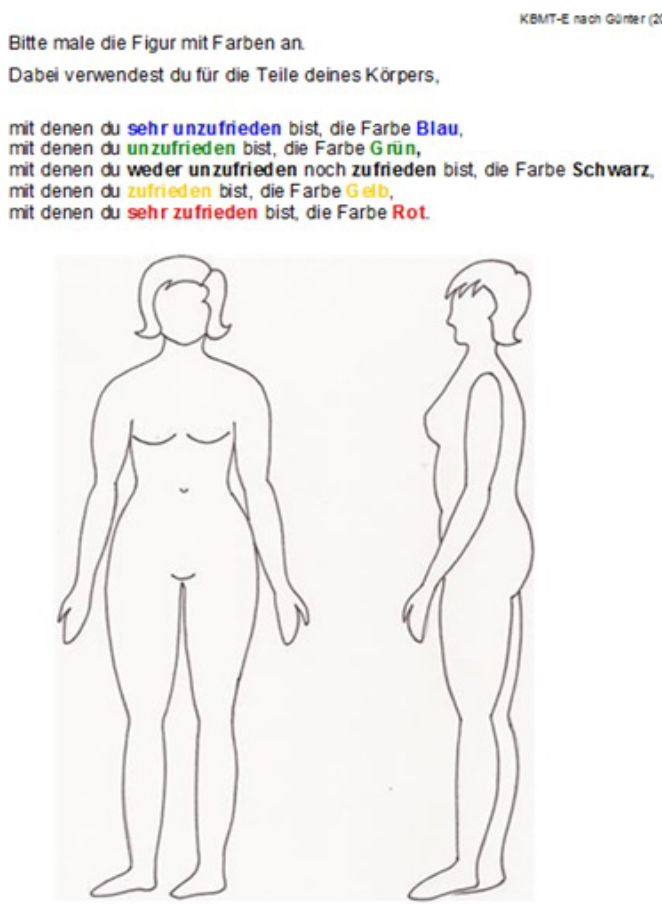

Figure 3:Colour-a-Person-Dissatisfaction-Test(Körperbildmaltest) female schema. 
Later the drawing tests were evaluated using a standardized evaluation scheme (Figure 4).

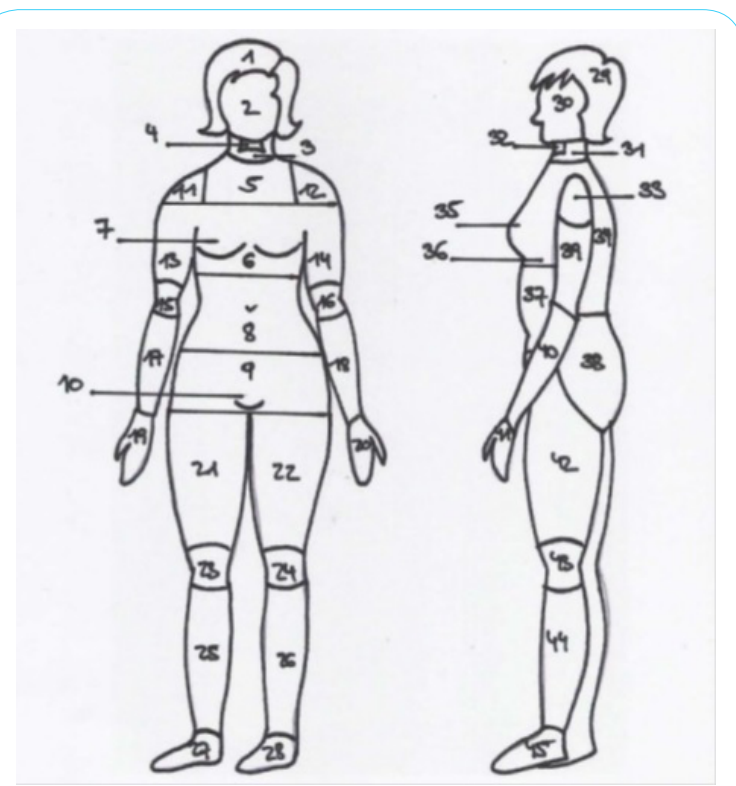

Figure 4: Evaluation scheme.

The satisfaction was graded by using an Austrian performance record (1-5, 1 being "very satisfied", 5 being "very unsatisfied"). The grades (=colours) of each region were added and an average grade was calculated.

The level of differentiation was evaluated by counting the differentiated coloured regions (in case of symmetric areas, such as ears, eyes, arms and legs the two regions counted as one if they were rated with the same colour) and later divided by the total number of regions (52). As a result, the maximum level of differentiation could reach " 1 " as a maximum (meaning that the tested person is aware of many different body areas), and 0,02 in case the interviewee coloured his / her body in only one colour (meaning that the body is not felt in differentiated regions).

\section{Setting}

83 Colour-a-Person-Dissatisfaction-Tests (=CaPDTs) (Körperbildmaltest) were carried out. 47 of these 83 were conducted with patients, who were hospitalized at the same hospital with the primary diagnosis "depression" with an additional diagnosis "burnout" for at least 1, max. 10 weeks. The group consisted of 24 female and 23 male patients, aged between 38 and 76. All patients were assigned by the chief resident and the participation was voluntary.

36 CaPDTs were carried out with a control group, all participants work for the same company and were diagnosed as "healthy" by the company's occupational physician. The control group consisted of 22 women and 14 men, aged between 18 and 55. The participation was voluntary.

\section{Results \& Discussion}

Not only do the results show a significant difference between the group suffering from burnout and the control group. It was useful to divide the patients into sub-categories. Two sub-categories were

formed of people showing distinct features in their CaPDTs, and a third group was formed, as they seemed to show less difference to the control group as the former two. Interestingly, the groups not only differed in their body satisfaction and ability to differentiate their bodies, but also showed that these factors improved over the time of hospitalization. In the following part, firstly the results will be presented in form of graphs, followed by an explanation. In the last section of this article, the conclusion of the findings will be presented.

\section{All patients vs. control group}

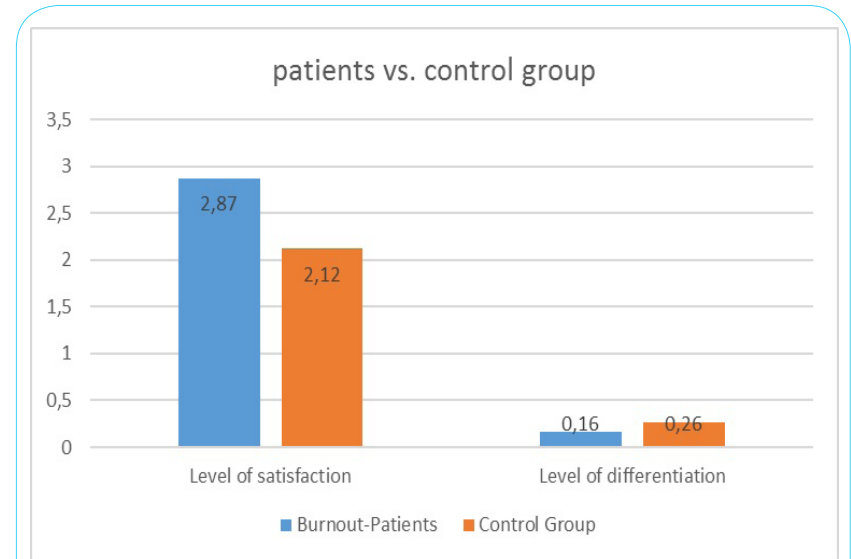

Figure 5: Patients vs. control group.

The graph (Figure 5)) shows the difference between the sum of all interviewed patients and the control group. It can be seen, that the control group is more satisfied with their body $(2,12$ vs. 2,87$)$ and has a higher level of differentiation $(0,26$ vs. 0,16$)$. The detected differences between the group of Burnout-patients and the control group regarding body-satisfaction and -differentiation are not based on coincidence, but underlie a systematic effect. Both samples originate from diverse populations. The significance level is less than $1 \%$ (psatisfaction $=0,000112466$, pdifferentiation $=0,0000643282$ ) regarding the dependent variables and thus can be seen as very significant.

After showing that there is a significant difference between burnout patients and the control group, sub-categories of the burnout-patients will be formed, as the results of tests were very different. Firstly these differences will be shown by numbers, followed by examples of the tested people.

In this graph (Figure 6), it can be seen, that the burnout-types I \& II are located on the far ends of the spectrum of satisfaction. Type I

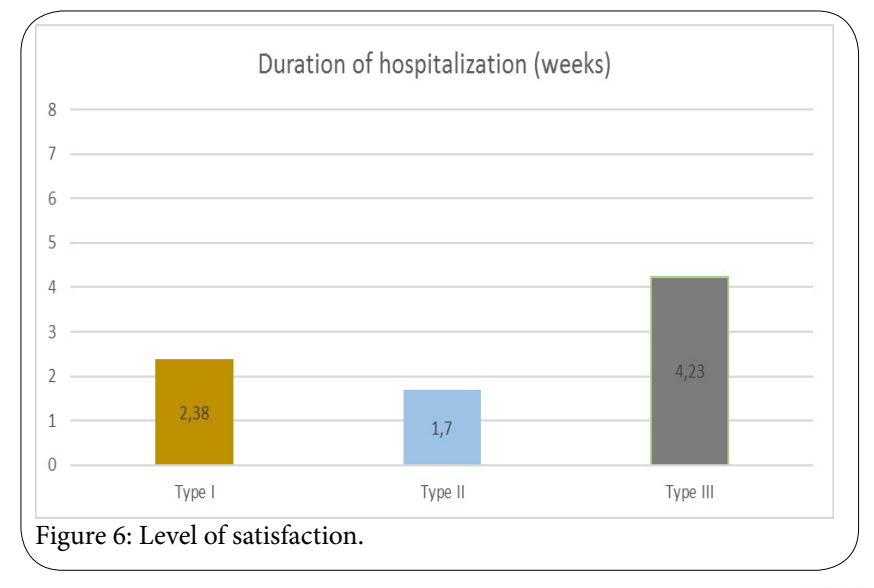


shows a very low satisfaction with its body, standing at 3,7 , whereas Type II seems to be very satisfied, standing at 1,59 . Type III $(2,94)$ can be found at the middle of the spectrum. The control group $(2,12)$ can be found between Type II \& III. The detected differences between the various types of Burnout-patients regarding body-satisfaction are not based on coincidence, but underlie a systematic effect. All samples originate from diverse populations. The significance level is less than $1 \%\left(\mathrm{p}_{\text {satisfactionTI-TII }}=0,000013, \mathrm{p}_{\text {satisfactionTI-TIII }}=0,000059\right)$ regarding the dependent variables and thus can be seen as very significant.

\section{Continued, Interrupted and Impulsive}

The level of differentiation shows that again, Type I \& II can be found at the wide end of the spectrums (Figure 7 ). This time however, they are on the same side. Members of Type I $(0,15)$ and II $(0,09)$ show a very low level of differentiation, whereas Type III $(0,19)$ is closer to the results of the control group $(0,26)$. The detected differences between the various types of Burnout-patients regarding body-differentiation are not based on coincidence, but underlie a systematic effect. All samples originate from diverse populations. The significance level is less than $1 \%\left(\mathrm{p}_{\text {differentiationTI-TIII }}=0,000011\right)$ regarding the dependent variables and thus can be seen as very significant.

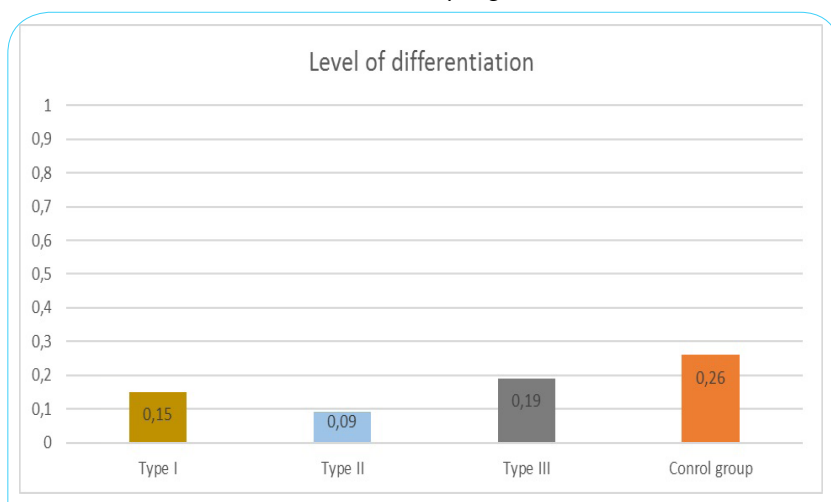

Figure 7: Level of differentiation.

\section{Duration of hospitalization}

The graph above (Figure 8) shows the average duration of hospitalization of the patients at the point of the testing. It can be seen that the members of Type I \& II had been hospitalized recently, Type I 2,38 weeks, Type II 1,7 weeks, whereas Type III-patients had already been at the clinic for a longer period of time ( 4,23 weeks).

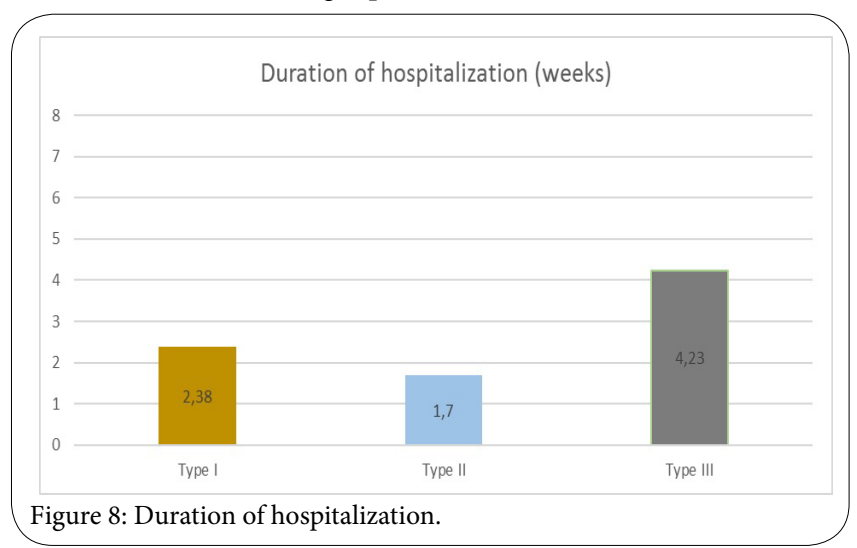

The sub-categories of Burnout-patients

After showing the significant differences between the various burnout-patients, the following part of this article intends to characterize the different types.

\section{Type I - the selective type}

This group of patients shows a very specific way of coloring the body image drawing test. Instead of coloring the entire schema, these patients only choose to highlight very few areas. These selected areas are mostly represented as being "very unsatisfied" or "unsatisfied" with. It can be said, that these patients only feel their body in case of pain. Both their levels of satisfaction (level of satisfaction 3,7) and differentiation $(0,15)$ are very low. The following figure (Figure 9) shows the results of a typical patient of this group. Out of 47 patients, 12 (7 male, 5 female) represent this group $(25,53 \%)$. The members of this group had been hospitalized by an average of 2,4 weeks upon the testing took place.
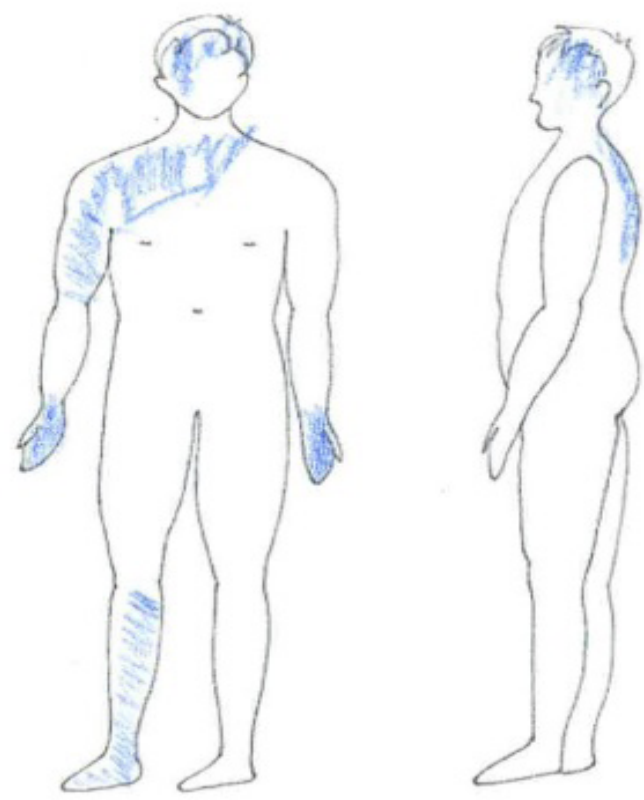

Figure 9: "selective type".

\section{Type II - the totalitarian type}

The totalitarian type seems to be very satisfied with his / her body. The level of satisfaction is very high $(1,59)$. However, as mentioned before, a high level of satisfaction alone does not "safe" one from burnout. In this case, the patients level of differentiation is very low $(0,09)$, meaning that the members of this group lack a stable self, which would involve a certain level of differentiation. Out of 47 patients, nine can be classified as totalitarian types (19,15\%), five man and four women. To be classified as a type II-patient, one has to cover the body schema with one color completely, using colors which either represent "satisfied" or "very satisfied". Only one additional color is allowed, covering a maximum of two small regions (for example the shoulders or hands). Members of this group had been hospitalized by an average of 1,7 weeks at the time they were tested. In figure 11a a typical member of this group can be seen.

\section{Type III - the differentiated type}

This type is the closest to the control group, with an average of level of satisfaction $(2,94)$ and a higher level of differentiation $(0,19)$ than the other two types. $55,32 \%$ of the patients, that is 26 out of 47,14 female and 12 male, belong to this type. These results, however, are not surprising, as the members of this group had been in therapy for an average of 4,23 weeks when they were tested. In figure $11 \mathrm{~b}$ a 
member of this group can be seen, beside a member of the control group.

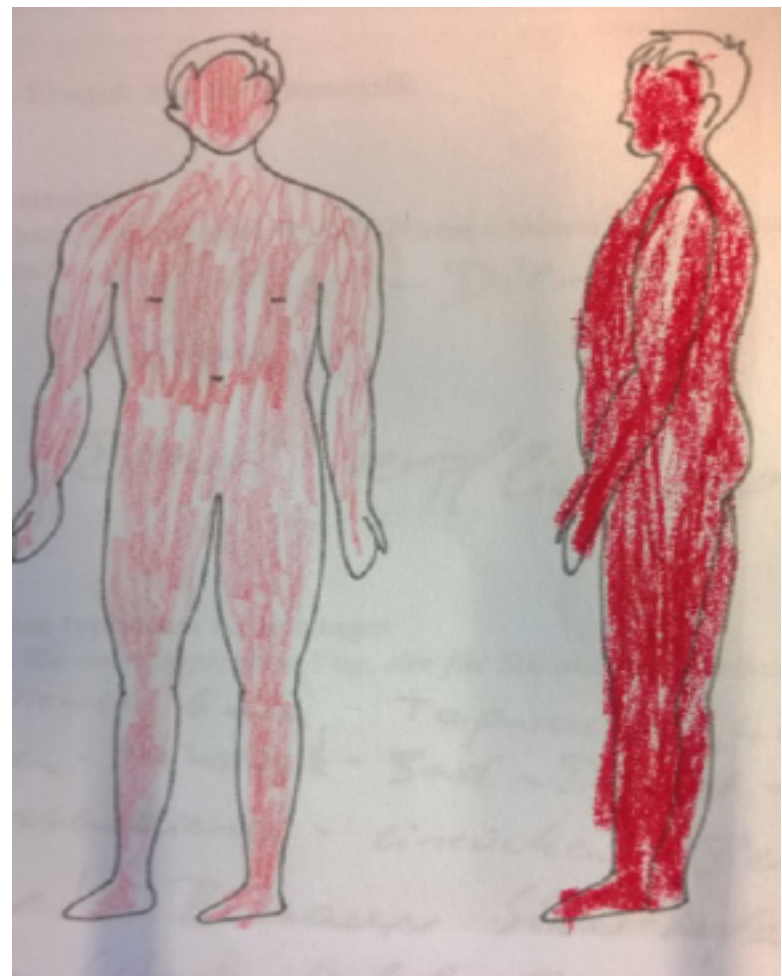

Figure 10: "totalitarian type”.

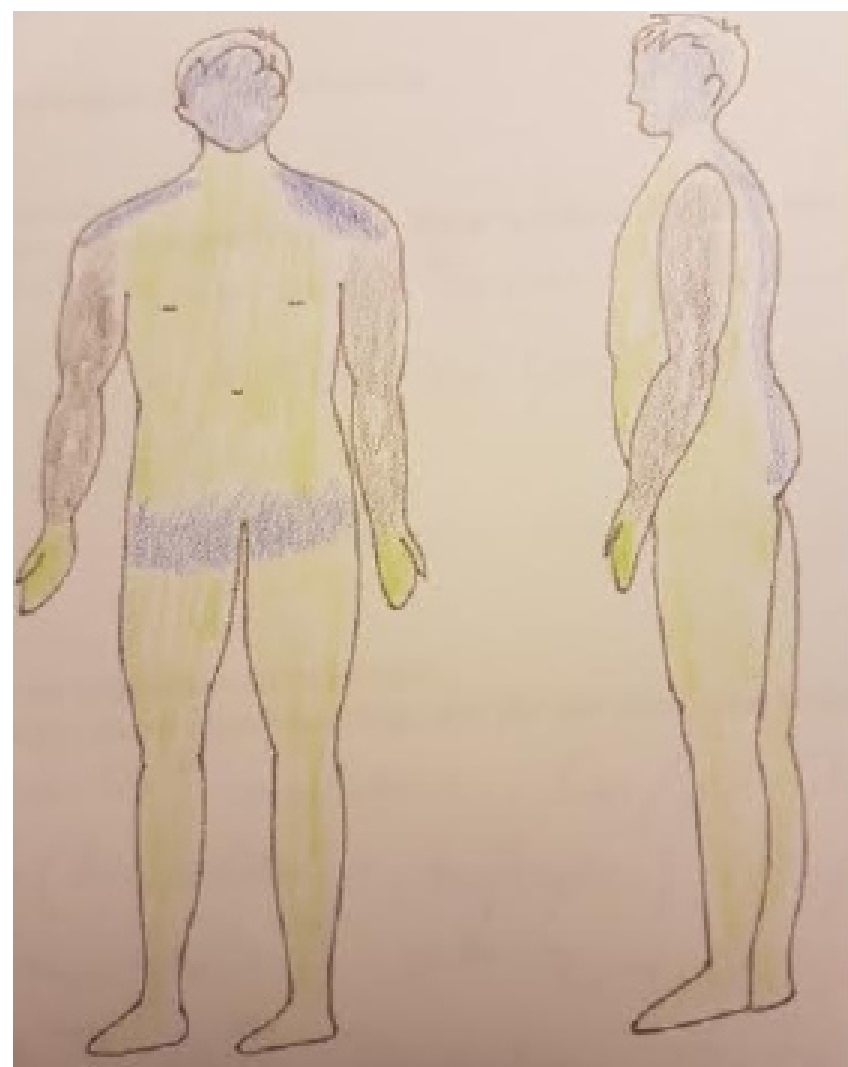

Figure 11a: "Differentiated type".

\section{Results \& Discussion}

The findings show a wide range of results, and it is impossible to cover and interpret all of them in one article. Referring to Bielefeld's body image and the three subcategories body consciousness, body boundary and body attitude, it can be said, that mostly the body consciousness and the body attitude play a big role in this study. Burnout patients, especially in the early stages of therapy, seem not to be conscious of their bodies. Either they experience it as one whole, without being able to differentiate between body parts, or they experience only disconnected areas of pain. Either way, the level of differentiation is very low. The two types, who had not experienced a lot of therapy, due to the fact that their hospitalization had not been long before the testing, show a severe difference in level of satisfaction, however over the course of the therapy they experience, these levels approach the levels of the control group. These results underline the importance of therapy.

To sum up the findings regarding the types of Burnout-patients, it can be said, that at the beginning of their hospitalization, the patients can be divided into two groups. One of them with a very low level of body satisfaction (Type I-selective type), and the other with a very high level of satisfaction (Type II-totalitarian type). Both groups however, share a very low level of differentiation, compared to the control group. An explanation for this phenomenon might be the following - Type I patients feel their body as "broken". This broken feeling expresses itself through the pain the patients feel. When reflecting upon their body, these section dominate the entire selfreflexion of the patients and only allows them to focus on these few areas. The Type-2 patients on the other hand, feel their bodies as one

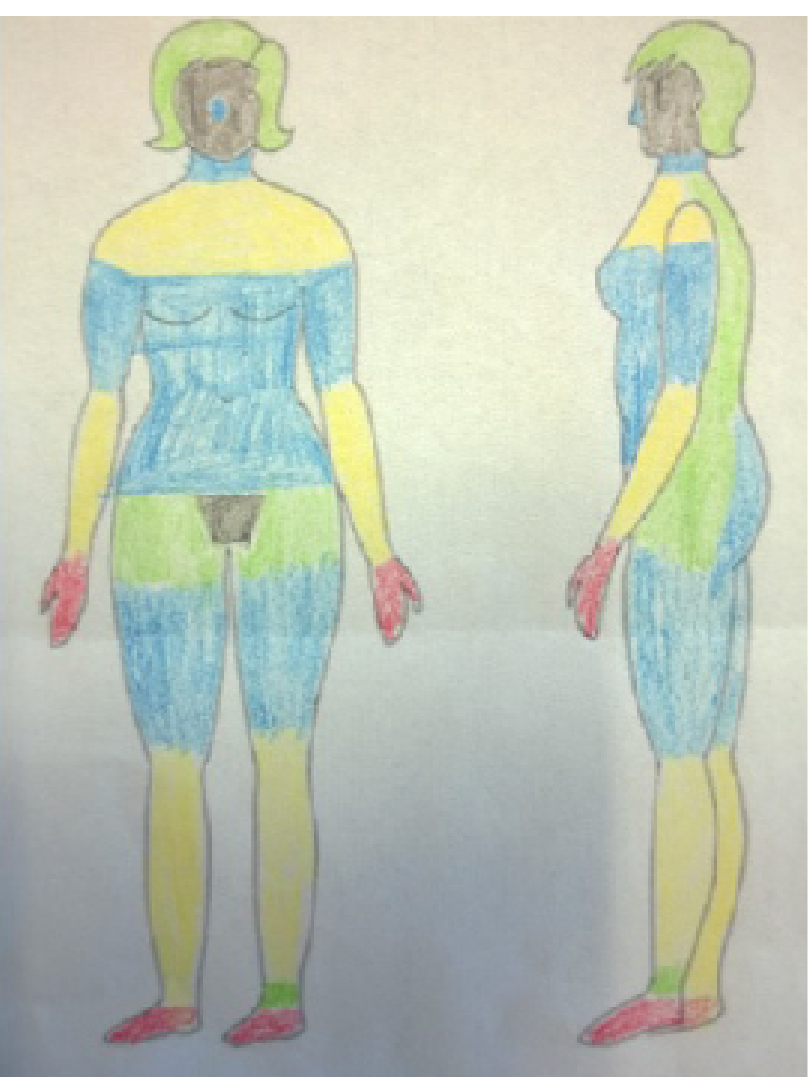

Figure 11b: "control group". 
total image. They are incapable of differentiating their body, and since they feel better after some time at the clinic, they tend to completely polarize into one direction, in their case a satisfied one, without having the ability to differentiate. This theory is also supported by the fact, that both extreme types approach a "middle" status after an average of four weeks in therapy. This Type III shows a higher ability to differentiate positive and negative feelings toward the own body and through this takes the first steps towards an approximation to the control group. After about four weeks of hospitalization and therapy, the burnoutpatients show a higher level of differentiation, yet the difference to the control group is still significant. Furthermore, the control group shows a higher satisfaction with their bodies, which leads to the conclusion that Burnout-patients not only suffer from emotional exhaustion, but that also their conception of their body is dysregulated. This picture is not unique for Burnout, as many specialists describe this pathology with other diseases as well, e.g. anorexia nervosa [18], adiposity [19] and bulimia nervosa [19]. It can be assumed that the body image and the perception of the body of Burnout-patients are as dysregulated as the ones of patients with other psychological disturbances.

\section{Competing Interests}

The authors declare that they have no competing interests.

\section{Acknowledgements}

The project An Interdisciplinary Inquiry On Regular Body Rhythm and its Dysfunctions Nr. P 26110-G15 (R. Esterbauer, A. Paletta) was funded by the Austrian Science Fund and Austrian University Research Sector.

\section{References}

1. Richter R (2012) BPtK - Studie zur Arbeitsunfähigkeit. Psychische Erkrankungen und Burnout 2012

2. Friedl W (2006) Österreichs erste große Burnoutstudie. Eine Ursachenanalyse als repräsentative Grundlage zur Entwicklung von Gegenstrategien als Ausweg aus der Krise. In Business Doctors (Ed.) Österreichs erste große Burnoutstudie. Eine Ursachenanalyse als repräsentative Grundlage zur Entwicklung von Gegenstrategien als Ausweg aus der Krise. Graz: Business Doctors Inernational HRM \& Business Consulting Network.

3. Hedderich I (2009) Burnout - Ursachen, Formen, Auswege. München: Verlag C.H. Beck oHG

4. Maslach C, Jackson S (1982) The measurement of experienced bumout. J Occup Behav2: 99-113.

5. Savicki V, Cooley E (1983) Theoretical and research considerations of burnout. Children and Youth Services Review 5: 227-238.

6. Deutsches Institut Für Medizinische Dokumentation und Information (Ed.) (1994) 1CD-10-Internationale statistische Klassifikation der Krankheiten und verwandter Gesundheitsprobleme Revision. Band I: Systematisches Verzeichnis. München: Urban u. Schwarzenberg

7. Weber A, Jaeckel-Reinhard A (2000) Burnout syndrome: a disease of modern societies? Occup. Med (Lond) 50: 512-517.

8. Litzcke S, Schuh H (2010) Stress, Mobbing, Burnout am Arbeitsplatz. Heidelberg: Springer

9. Slade $\mathrm{P}$ (1988) Body image in anorexia nervosa. Br J Psychiatry Suppl 153: $20-22$.

10. Schilder P (1935) The Image and Appearance of the Human Body: Studies in the Constructive Energies of the Psyche. London: K. Paul, Trench, Trubner \& Company Limited.

11. Stice E, Rohde P, Shaw H (2013) The Body Project. Oxford: University Press.

12. Kiener F (1973) Untersuchungen zum Körperbild (Body Image), 1.Teil Zeitschrift für klinische Psychologie und Psychtherapie, 21: 336
13. Müller E (2003) Ausgebrannt - Wege aus der Burnout-Krise. Freiburg im Breisgau: Verlag Herder.

14. Bielefeld J (1991) Körpererfahrung - Grundlagen menschlichen Bewegungsverhaltens. Göttingen: Verlag für Psychologie, p. 3, 17

15. Köppl M (2006) Ausgebrannt?! - Strukturwandel und Burnout-Syndrom in sozialen Berufen. VDM Verlag Dr. Müller, Saarbrücken.

16. Günter M (2009) Körperbildforschung bei Kindern mit Hilfe des Körperbildmaltests für Kinder (KMBT-K). In: Joraschky P, Loew T, Röhricht F (Ed.) Körpererleben und Körperbild. Ein Handbuch zur Diagnostik. Stuttgart: Schattauer.

17. Bruch H (1962) Perceptual and conceptual disturbances in anorexia nervosa. Psychosom Med; 24: 187-194.

18. Geiger H (2008) Der Zusammenhang zwischen Körperbild und Essverhalten: Eine Untersuchung anhand des Körperbildmaltests für Erwachsene. Diplomarbeit, Eberhard Karls Universität. Tübingen

19. Breitenöder-Wehrung A, Kuhn G, Günter M, Neu A (1998) Comparison oft he body image of healthy and psychiatrically and chronically ill children using the KBMT-K. Psychother Psychosom Med Psychol 48: 483-490.

20. Glawischnig S (2010) Intervention bei übergewichtigen und adipösen Erwachsenen durch ein polysportives Bewegungsangebot. Karl Franzens Universität Graz, Graz, Austria. 